\title{
DUKUNGAN SISTEM INFORMASI MANAJEMEN KEPEGAWAIAN TERHADAP PENGAMBILAN KEPUTUSAN DI BKPP KABUPATEN SUKOHARJO
}

\author{
Riana Isti Muslikhah \\ Jurusan Pendidikan Administrasi, Fakultas Ekonomi Universitas Negeri Yogyakarta, Indonesia \\ riana.muslikhah@uny.ac.id
}

\begin{abstract}
Abstrak: Dukungan Sistem Informasi Manajemen Kepegawaian terhadap Pengambilan Keputusan di BKPP Kabupaten Sukoharjo. Tujuan penelitian ini adalah untuk (1) Mengetahui implementasi Sistem Informasi Manajemen Kepegawaian di BKPP Kabupaten Sukoharjo, (2) Mengetahui dukungan informasi yang dihasilkan oleh Sistem Informasi Manajemen Kepegawaian dalam pengambilan keputusan bidang kepegawaian di BKPP Kabupaten Sukoharjo,(3) Mengetahui kendala dalam implementasi Sistem Informasi Manajemen Kepegawaian di BKPP Kabupaten Sukoharjo. Penelitian ini menggunakan metode penelitian kualitatif. Hasil penelitian menunjukkan bahwa (1) Dalam proses penerapan SIMPEG di BKPP Kabupaten Sukoharjo terdapat sub sistem pengumpulan data, sub sistem input data, sub sistem pengolahan data dan sub sistem output informasi, serta didukung oleh komponenkomponen pendukung yang terdiri dari hardware (perangkat keras), software (perangkat lunak), database, sumber daya jaringan dan brainware (SDM). (2) Informasi yang dihasilkan oleh SIMPEG di BKPP saat ini sudah mampu mendukung dalam pengambilan keputusan penempatan, mutasi dan pensiun pegawai, (3) Kendala yang dihadapi dalam penerapan SIMPEG di BKPP Kabupaten Sukoharjo yaitu: keterbatasan anggaran dan keterlambatan dalam input data.
\end{abstract}

Kata kunci: Sistem, Informasi, Manajemen, Keputusan, Kepegawaian

Abstract: Human Resources Management Information System Support for Decision Making in BKPP Sukoharjo Regency. The purposes of this study were (1) to know the Implementation Human Resources Management Information Systems in BKPP of Sukoharjo Regency, (2) know the support information generated by Implementation Human Resources Management Information Systems in BKPP of Sukoharjo Regency in the field of staffing decisions. (3) know the obstacles in the Implementation Human Resources Management Information Systems in BKPP of Sukoharjo Regency. This study used qualitative research methods. The results showed that (1) In the Implementation Human Resources Management Information Systems in BKPP of Sukoharjo Regency there are sub data collection systems, sub system of data input, data processing sub-systems and sub systems output information, and supported by supporting parts consisting of hardware, software, databases, netware and brainware (2) The information generated by Human Resources Management Information Systems at BKPP of Sukoharjo Regency are now able to support decision making in placement, transfer and retirement of employees, but not fully support in the implementation of management staffing in the BKPP of Sukoharjo Regency. (3) The obstacle that is encountered in implementation of the Human Resources Management Information Systems in BKPP of Sukoharjo Regency are : limited budget and delays in data input.

Keyword: System, Information, Management, Decision Making, Human Resources 


\section{PENDAHULUAN}

Perkembangan teknologi informasi dan komunikasi berkembang semakin cepat di era globalisasi sekarang ini. Berkembangnya teknologi informasi dan komuniakasi memberikan konsekuensi bagi para pimpinan organisasi dalam pengambilan keputusan (decision making) (Sadat, 2019). Penggunaan teknologi informasi dan komunikasi dalam manajemen organisasi publik merupakan salah satu jawaban dari tantangan yang dihadapi oleh penyelenggaraan administrasi publik. Pemanfaatan teknologi informasi dalam berbagai aspek pengelolaan informasi dalam setiap instansi akan menghasilkan efisiensi yang ditunjukkan oleh kecepatan dan ketepatan waktu pemrosesan serta ketelitian dan kebenaran informasi (validitas) yang dihasilkan. Hal ini berkaitan dengan penggunaan perangkat keras (hardware), program aplikasi pendukung (software), perangkat komunikasi dan internet sebagai sarana pengelolaan informasi.

Penerapan teknologi informasi dalam pengelolaan data pegawai saat ini sangat penting karena akan mendukung terciptanya good governance. Penggunaan teknologi informasi akan berdampak pada tersedianya Informasi yang aktual serta akurat dalam pengambilan keputusan serta dapat membuat perubahan mengenai kepercayaan masyarakat kepada pemerintah. Dampak lain yang dapat dirasakan pemerintah adalah terjadinya perbaikan tugas-tugas yang dibebankan kepada aparatur negara, seperti tugas untuk mengolah, mengelola, menyalurkan dan mendistribusikan informasi dan pelayanan publik.

Teknologi informasi komunikasi tidak dapat dipisahkan dari sebuah organisasi, baik organisasi yang bergerak di dunia bisnis maupun yang bergerak di dunia sosial (Irawan, 2013). Investasi di bidang teknologi informasi komunikasi merupakan masalah yang sulit bagi pimpinan organisasi. Di satu pihak mereka sadar dan berfikir bahwa sudah saatnya organisasinya memiliki sistem informasi yang lebih baik dan tentunya di dukung oleh alat yaitu teknologi informasi komunikasi untuk menunjang sistem kerja bagi organisasi mereka. Tanpa memiliki TI yang cukup canggih, sulit pada lingkungan global ini untuk mampu bersaing atau memberikan pelayanan yang lebih baik kepada customer (Indrajit, 2004).

Pentingnya teknologi informasi pernah dikaji dalam berbagai penelitian dan hasilnya telah membuktikan kemampuannya dalam meningkatkan kinerja instansi pemerintahan daerah dalam menjalankan tugasnya. Penelitian Irawan dan Waskito (2011) menunjukkan bahwa sistem yang komputerisasi mampu meminimalisir terjadinya kesalahan seperti banyak terjadi pada sistem manual.

Dalam menghadapi pertumbuhan dan pembangunan suatu organisasi yang sudah demikian kompleksnya dibutuhkan tersedianya suatu sistem informasi manajemen yang mampu untuk membantu penyediaan data dan informasi sebagai bahan penentuan kebijaksanaan dan strategi pembangunan maupun bagi tersedianya data dan informasi operasional (Komorotomo dan Margono, 
2004). Penggunaan sistem informasi manajemen kepegawaian berguna untuk memperkecil biaya, meningkatkan komunikasi, dan mengurangi waktu untuk menyelesaikan aktivitas yang berhubungan dengan kepegawaian (Beadless, Lowery dan Johns, 2005).

Semua proses pengambilan keputusan di organisasi pemerintahan memerlukan keterpaduan informasi yang akurat dan terpercaya agar keputusan yang dihasilkan dapat berdaya guna, misalnya pengambilan keputusan dalam bidang kepegawaian. Salah satu upaya yang dilakukan oleh pemerintah untuk menciptakan sistem administrasi kepegawaian yang baik serta dalam rangka menanggapi perkembangan teknologi informasi dan komunikasi yang semakin pesat yaitu dengan mengembangkan sistem informasi manajemen kepegawaian. Pokok pelaksanaan Sistem Informasi Manajemen Kepegawaian (SIMPEG) telah tercantum dalam Keputusan Mendagri Nomor 17 Tahun 2000 tentang Sistem Informasi Manajemen Kepegawaian Departemen Dalam Negeri dan Pemerintah Daerah.

Selama beberapa dekade terakhir, organisasi telah menggunakan SIMPEG lebih banyak untuk mengelola potensi pegawai mereka (Ngai \& Wat, 2006). SIMPEG adalah perangkat lunak, perangkat keras, fungsi pendukung, kebijakan dan prosedur sistem terintegrasi ke dalam proses sistem otomatis yang mendukung proses strategis dan operasional departemen SDM dan manajernya (Chauhan, Sharma, \& Tyagi, 2011). Pada tingkat fungsional, SIMPEG dapat melacak kondisi karyawan, pelamar, dan kondisi pekerja kontingen, demografi, penilaian kinerja, pengembangan profesional, penggajian, perekrutan, dan retensi (Troshani, et al., 2011).

SIMPEG di Badan Kepegawaian, Pendidikan dan Pelatihan Kabupaten Sukoharjo telah dikelola oleh Bidang Pembinaan dan Informasi Data Pegawai. SIMPEG ini dimaksudkan untuk membantu pimpinan dalam pengambilan keputusan tentang kepegawaian. Dalam pelaksanaannya perkembangan teknologi informasi dan komunikasi yang semakin pesat akan selalu mempengaruhi sebuah sistem informasi dalam suatu organisasi. Oleh karena itu, BKPP Kabupaten Sukoharjo melakukan modernisasi administrasi dengan menerapkan SIMPEG berbasis web. Dengan adanya SIMPEG berbasis web diharapkan manajemen Pegawai Negeri Sipil (PNS) yang meliputi kegiatan perencanaan kepegawaian, rekrutmen, mutasi pegawai, kenaikan jabatan, penilaian kinerja pegawai, kenaikan pangkat, kenaikan gaji berkala, pelatihan, dan pensiun di lingkungan Pemerintah Kabupaten Sukoharjo dapat didukung oleh informasi SIMPEG. Namun, pada kenyataannya saat ini SIMPEG di BKPP Kabupaten Sukoharjo belum sepenuhnya mendukung pengambilan keputusan dalam pelaksanaan manajemen kepegawaian.

Berdasarkan latar belakang yang telah dikemukakan di atas, maka peneliti akan mengkaji lebih dalam mengenai "Dukungan Sistem Informasi Manajemen Kepegawaian terhadap Pengambilan 
Keputusan di BKPP Kabupaten Sukoharjo" dalam penelitian ini. Dalam tulisan ini akan dibahas mengenai penerapan SIMPEG di BKPP Kabupaten Sukoharjo, dukungan SIMPEG terhadap pengambilan keputusan bidang kepegawaian serta kendala yang dihadapi dalam penerapan SIMPEG.

\section{METODE}

Bentuk penelitian ini menggunakan paradigma penelitian deskriptif kualitatif yang dilakukan terhadap variabel mandiri, yaitu tanpa membuat perbandingan atau menghubungkan dengan variabel lain. Peneliti tidak memberikan perlakuan apapun terhadap objek penelitian sehingga objek dibiarkan seperti kondisi aslinya secara apa adanya. Penelitian kualitatif diarahkan pada kondisi aslinya, bahwa datanya ditanyakan pada keadaan apa adanya sesuai dengan yang ada di lapangan. Sedangkan deskriptif dimaksudkan bahwa penelitian bertujuan mendeskripsikan data berdasarkan kenyataan dilapangan dengan kata-kata, uraian ataupun penjelasan cara untuk memecahkan masalah dengan menjabarkan fakta-fakta yang tampak sebagaimana adanya.

Dalam penelitian ini untuk mencari data yang dibutuhkan peneliti menggunakan berbagai sumber data yaitu informan, tempat dan peristiwa, dan dokumen. Informan dalam penelitian ini yaitu staff BKPP Kabupaten Sukoharjo yang mengelola SIMPEG, Kepala Bidang dan Sub Bidang serta Kepala BKPP Kabupaten Sukoharjo.

Pengujian validitas data dalam penelitian ini menggunakan teknik triangulasi. Teknik triangulasi yaitu cara memeriksa keabsahan data dengan menggunakan cara yang lain. Triangulasi yang digunakan yaitu triangulasi data dan triangulasi metodologi. Analisis data menggunakan teknik analisis data interaktif. Analisis data interaktif terdiri dari tiga komponen yaitu reduksi data, penyajian data dan penarikan kesimpulan.

\section{HASIL DAN PEMBAHASAN}

\section{Penerapan Sistem Informasi Manajemen Kepegawaian di Badan Kepegawaian, Pendidikan}

\section{dan Pelatihan Kabupaten Sukoharjo}

Sistem Informasi Manajemen Kepegawaian (SIMPEG) di Badan Kepegawaian, Pendidikan dan Pelatihan (BKPP) Kabupaten Sukoharjo mulai diterapkan pada tahun 2002. Dana yang digunakan untuk pengembangan SIMPEG ini bersumber dari Anggaran Pendapatan dan Belanja Daerah Kabupaten Sukoharjo. Penerapan SIMPEG ini bertujuan untuk mempermudah manajemen pegawai negeri sipil di Kabupaten Sukoharjo. Aturan yang mendasari diterapkannya SIMPEG di BKPP Kabupaten Sukoharjo adalah Undang- Undang No.17 Tahun 2000 tentang Sistem Informasi Manajemen Kepegawaian Departemen Dalam Negeri dan Pemerintah Daerah. 
Prosedur pelaksanaan SIMPEG di BKD Kabupaten Sukoharjo terdiri dari sub sistem pengumpulan data, sub sistem input data, sub sistem pengolahan data dan sub sistem output informasi. Sumber data yang dijadikan dasar dalam pengelolaan SIMPEG di BKD Kabupaten Sukoharjo berasal dari Formulir Isian Pegawai. Mulai tahun 2017, Sistem Informasi Manajemen Kepegawaian di BKPP Kabupaten Sukoharjo di upgrade menjadi sistem SIMPEG online sehingga dapat diakses darimanapun dan kapanpun untuk mempernmudah kinerja Pegawai Negeri Sipil di Kabupaten Sukoharjo yang berkaitan dengan administrasi kepegawaian. Sebelumnya, BKPP Kabupaten Sukoharjo menerapkan SIMPEG berbasis web dengan jaringan LAN.

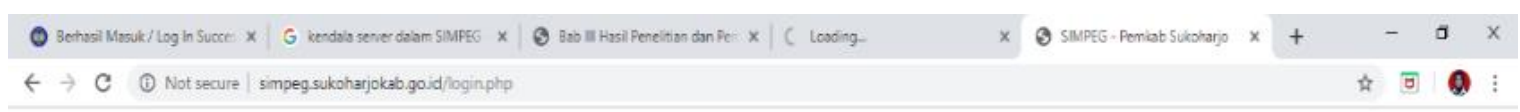

\section{Sistem Informasi Manajemen Kepegawaian \\ Pemerintah Kabupaten Sukoharjo}

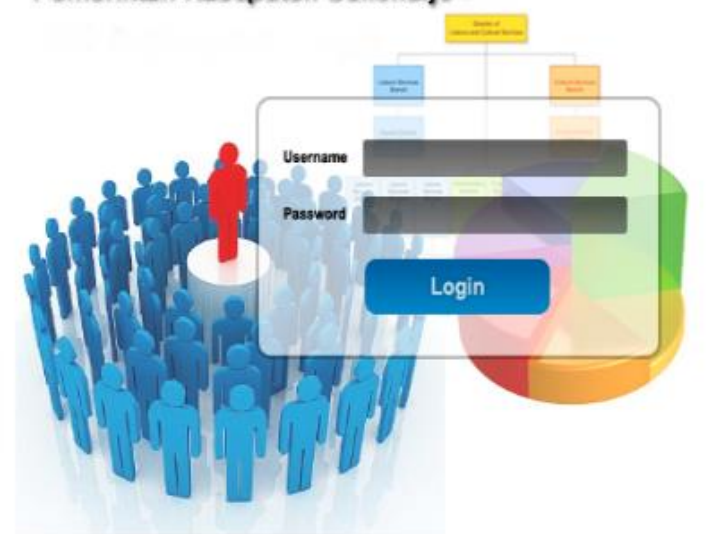

Gambar 1. Tampilan Sistem Informasi Manajamen Kepegawaian di BKPP Sukoharjo

Penerapan sebuah sistem informasi sangat dipengaruhi oleh lima komponen, demikian dalam implementasi SIMPEG di BKPP Kabupaten Sukoharjo sangat dipengaruhi oleh lima komponen tersebut. Lima komponen itu meliputi: 1) Sumber Daya Perangkat Keras (Hardware), 2) Sumber Daya Perangkat Lunak (Software),3) Sumber Daya Basis Data (Database), 4) Sumber Daya Jaringan (Netware) dan 5) Sumber Daya Manusia.

Pengolahan data SIMPEG di BKPP Kabupaten Sukoharjo melalui beberapa tahapan sebagaimana dalam tahapan pengolahan data Sistem Informasi Manajemen pada umumnya. Dalam pengolahan data SIMPEG di BKPP Kabupaten Sukoharjo terdapat proses coding, classifying, calculating, summarizing, displaying dan reproducing. 
Berdasarkan hasil penelitian diperoleh kesimpulan bahwa output yang dihasilkan oleh SIMPEG di BKPP Kabupaten Sukoharjo berupa:

a) Biodata Pegawai

b) Rekapitulasi Jumlah Pegawai

c) Daftar Urut Kepangkatan

d) Daftar Nominatif Pegawai

e) Nominatif Pegawai yang akan Pensiun

Output yang dihasilkan oleh SIMPEG di BKPP Kabupaten Sukoharjo bermanfaat untuk:

a) Mempermudah proses pencatatan dan pendataan pegawai

b) Mempermudah penyimpanan dan akses terhadap database pegawai

c) Mempermudah pencarian dan cetak data sebagai bahan pelaporan, dan

d) Sebagai pendukung dalam pengambilan keputusan.

Penerapan SIMPEG di BKPP Kabupaten Sukoharjo dalam mendukung manajemen kepegawaian ini mendukung penelitian yang dilakukan oleh Pratiwi (2018) yang dalam penelitianya menyebutkan bahwa dengan implementasi SIMPEG dapat membantu BKDiklatda untuk mengelola data kepegawaian di Pemerintah Kota Salatiga secara cepat, tepat, dan akurat. Penelitian sejenis yang dilakukan oleh Ferdous, Chowdury dan Buiyan (2015) juga mengemukakan bahwa implementasi Sistem Informasi Sumber Daya Manusia mampu mengendalikan tindakan sumber daya manusia dan mempercepat pengambilan keputusan SDM.

\section{Dukungan Informasi Sistem Informasi Manajemen Kepegawaian terhadap Pengambilan} Keputusan Kepegawaian di Badan Kepegawaian, Pendidikan dan Pelatihan Kabupaten Sukoharjo

Badan Kepegawaian, Pendidikan dan Pelatihan Kabupaten Sukoharjo adalah organisasi yang bertugas dalam pelaksanaan manajemen Pegawai Negeri Sipil di lingkungan pemerintah Kabupaten Sukoharjo. Sebagai organisasi yang bertugas dalam pelaksanaan manajemen kepegawaian tentunya memerlukan informasi yang cepat, tepat dan akurat dalam rangka pengambilan keputusan tentang kepegawaian. Informasi SIMPEG diharapkan dapat digunakan sebagai pendukung pengambilan keputusan di bidang kepegawaian. Informasi yang dihasilkan oleh SIMPEG akan meningkatkan efisiensi dan kualitas dalam pengambilan keputusan (Barkha, 2013;Lipursari, 2013). Informasi yang dihasilkan oleh SIMPEG di BKPP Kabupaten Sukoharjo saat ini sudah mendukung dalam pengambilan keputusan penempatan pegawai, mutasi pegawai dan pensiun pegawai. 


\section{a. Dukungan Informasi Sistem Informasi Manajemen Kepegawaian dalam Pengambilan Keputusan Penempatan Pegawai}

Penempatan pegawai adalah suatu kegiatan dalam manajemen PNS. Penempatan pegawai dilakukan setelah dilakukan proses seleksi penerimaan CPNS yang meliputi beberapa rangkaian tes. Pelamar yang dinyatakan diterima sebagai CPNS akan ditempatkan pada unit kerja sesuai dengan bidang keahlian yang dimiliki dan formasi yang telah disusun sebelum diselenggarakannya rekrutmen. Dalam pelaksanaan pengambilan keputusan penempatan pegawai dibutuhkan informasi yang valid dan akurat agar penempatan pegawai dapat berjalan sesuai apa yang diharapkan dan pegawai tersebut dapat ditempatkan di Satuan Kerja yang benar-benar membutuhkan.

Dari hasil penelitian, output yang dihasilkan SIMPEG di BKPP Kabupaten Sukoharjo memang sudah terdapat rekapitulasi pegawai berdasarkan satuan kerja. Oleh karena itu, dari output tersebut pengambil keputusan dapat melihat kekuatan satuan kerja sebagai dasar penyusunan formasi CPNS.

\section{b. Dukungan Informasi Sistem Informasi Manajemen Kepegawaian dalam Pengambilan}

\section{Keputusan Mutasi Pegawai}

Pimpinan dalam suatu organisasi pemerintahan dapat melakukan kebijakan mutasi pegawai. Pelaksanaan mutasi pegawai di Badan Kepegawaian, Pendidikan dan Pelatihan Kabupaten Sukoharjo ini menjadi tugas Bidang Pengangkatan, Pemberhentian dan Pemindahan khususnya Sub Bidang Pemindahan. Dalam melakukan mutasi pegawai, pengambil keputusan memerlukan informasi sebagai pendukung dalam pengambilan keputusan. Informasi yang dibutuhkan tersebut telah didapatkan dari SIMPEG di BKPP Kabupaten Sukoharjo.

Berdasarkan hasil penelitian, informasi yang dihasilkan oleh SIMPEG di BKPP Kabupaten Sukoharjo memang sudah mampu untuk mendukung pengambilan keputusan untuk melakukan mutasi pegawai. Hal tersebut dikarenakan output yang dihasilkan oleh SIMPEG sudah terdapat biodata lengkap pegawai yang disertai riwayat pegawai dan riwayat mutasi, serta rekapitulasi data pegawai di satuan kerja sehingga informasi tersebut dapat dijadikan pertimbangan dalam pengambilan keputusan oleh Bidang Pengangkatan Pemberhentian dan Pemindahan di BKPP Kabupaten Sukoharjo.

\section{c. Dukungan Informasi Sistem Informasi Manajemen Kepegawaian Dalam Pengambilan}

\section{Keputusan Pensiun Pegawai}

Pemberhentian (Pensiun) merupakan siklus yang pasti dialami dan tidak dapat 
dihindari oleh seluruh Pegawai Negeri Sipil. Untuk mengetahui pegawai yang akan memasuki masa pensiun, Sub Bidang Pengangkatan dan Pemberhentian di BKPP Kabupaten Sukoharjo memerlukan informasi yang tepat mengenai pegawai yang telah dan akan memasuki Batas Usia Pensiun (BUP).

Berdasarkan hasil penelitian Sistem Informasi Manajemen Kepegawaian di Kabupaten Sukoharjo sudah mendukung dalam pengambilan keputusan pensiun pegawai karena output SIMPEG yang dihasilkan oleh BKPP Kabupaten Sukoharjo sudah menghasilkan informasi Nominatif Pegawai yang akan pensiun. Namun, Laporan Nominatif Pegawai yang akan pensiun yang dihasilkan selama ini masih bersifat umum dan belum dibedakan berdasarkan jenis jabatan, misalnya guru, dokter, pejabat struktural, dsb.

SIMPEG di BKPP Kabupaten Sukoharjo sudah mampu mendukung pengambilan keputusan penempatan, mutasi dan pensiun pegawai sedangkan kenaikan gaji berkala, kenaikan pangkat dan penyelenggaraan Diklat belum didukung oleh SIMPEG. Hal tersebut dikarenakan output yang dihasilkan oleh SIMPEG di BKPP Kabupaten Sukoharjo masih terbatas dan belum menyediakan informasi untuk mendukung pengambilan keputusan kenaikan pangkat, kenaikan gaji berkala dan penyelenggaraan Diklat.

Nilai dalam suatu sistem informasi berhubungan dengan keputusan, dukungan sistem informasi manajemen pada pembuatan keputusan dalam suatu organisasi dapat diuraikan menurut tiga tahapan, proses pembuatan keputusan, yaitu pemahaman, perancangan (design), dan pemilihan (Anggadini, 2013). Sistem informasi manajemen yang baik dalam suatu organisasi akan dapat memberikan manfaat yang besar bagi pimpinan dalam pengambilan keputusan.

Sistem Informasi Manajemen Kepegawaian di BKPP Kabupaten Sukoharjo sudah mampu mendukung dalam pengambilan keputusan mutasi Pegawai Negeri Sipil, penempatan Pegawai Negeri Sipil dan pensiun Pegawai Negeri Sipil di lingkungan pemerintah Kabupaten Sukoharjo. Hasil penelitian ini mendukung teori yang dikemukakan oleh Rivai (2005) menyatakan bahwa Sistem Informasi Sumber Daya Manusia terdiri atas aktivitas sebagai berikut: 1) Didapatnya melalui perekrutan; seleksi; penempatan; paramalan, perencanaan SDM; perencanaan karir; dan lain-lain. 2) Pemeliharaan melalui pemberian Kompensasi; Ganti Rugi; Keuntungan; Pelatihan; Keselamatan dan Kesehatan; dan Hubungan pekerja. 3) Pemanfaatan melalui Penempatan; Pembinaan Manajemen; Keterampilan Menginventarisasi; Penilaian Kinerja; dan Standar Prestasi. 4) Evaluasi melalui Riset personal; Analisis Ekonomi; Analisis SDM; Penilaian Potensi; dan Audit SDM. (Suwatno\&Priansa, 2011:342).

Temuan penelitian ini juga mendukung hasil penelitian yang dilakukan oleh Pratiwi 
(2018) bahwa SIMPEG ini telah dimanfaatkan oleh seluruh pihak baik di tingkat staf maupun kepala untuk menjalankan fungsi BKDiklatda Salatiga dan pengambilan keputusan, selain itu data yang diperoleh dari SIMPEG telah menjadi ujung tombak dari manajemen kepegawaian yang dilakukan oleh BKDiklatda Kota Salatiga.

\section{Sistem Informasi Manajemen di Badan Kepegawaian, Pendidikan dan Pelatihan}

\section{Kabupaten Sukoharjo}

Penerapan Sistem Informasi Manajemen Kepegawaian di BKPP Kabupaten Sukoharjo saat ini masih mengalami berbagai kendala, hal tersebut salah satunya dapat dilihat bahwa saat ini SIMPEG belum mampu memberikan informasi yang lengkap untuk mendukung pengambilan keputusan di bidang kepegawaian. Berdasarkan hasil penelitian, kendala yang dihadapi dalam penerapan SIMPEG yaitu:

a. Keterbatasan Anggaran

BKPP Kabupaten Sukoharjo dalam penerapan SIMPEG masih terkendala dengan masalah anggaran. Anggaran yang dialokasikan untuk SIMPEG tidak sesuai dengan kebutuhan. Masalah anggaran merupakan masalah penting dalam perkembangan teknologi. Anggaran yang terbatas mengakibatkan pengembangan suatu sistem informasi dapat terhambat. Minimnya anggaran menjadi salah satu kendala dalam penerapan SIMPEG di BKPP Kabupaten Sukoharjo. Permasalahan anggaran ini mengakibatkan SIMPEG di BKPP Kabupaten Sukoharjo belum dapat berjalan dengan optimal.

b. Keterlambatan dalam input data

Sistem Informasi Manajemen Kepegawaian dituntut untuk menghasilkan informasi yang valid, up to date dan akurat sebagai pendukung dalam pengambilan keputusan kepegawaian - Agar selalu mendapatkan informasi yang valid, up to date dan akurat ini database kepegawaian harus di update. Saat ini dalam implementasi SIMPEG di BKPP Kabupaten Sukoharjo masih mengalami kendala dalam update database karena input data sering kali mengalami keterlambatan.

Salah satu faktor yang mempengaruhi keterlambatan dalam input data yaitu kurangnya koordinasi antar bidang yang ada di BKPP Kabupaten Sukoharjo. Berdasarkan hasil penelitian diketahui bahwa kepala bidang seringkali terlambat dalam melaporkan perubahan data kepegawaian sehingga data kepegawaian dalam SIMPEG menjadi kurang update.

c. Kurangnya pegawai pengelola SIMPEG

Sumber daya manusia adalah bagian terpenting dari sistem informasi terlibat dalam pembuatan sistem informasi, pengumpulan dan pengolahan data, pendistribusian dan pemanfaatan 
informasi yang dihasilkan oleh sistem informasi. Tanpa adanya sumber daya manusia, aplikasi Sistem Informasi Manajemen yang sebagus apapun tidak akan dapat berjalan dengan baik.

Penerapan SIMPEG di BKPP Kabupaten Sukoharjo belum dapat berjalan maksimal karena kurangnya sumber daya pengelola SIMPEG. Selama SIMPEG diterapkan di BKPP Kabupaten Sukoharjo, hanya ada satu orang pegawai yang bertanggungjawab terhadap pengolahan data dalam SIMPEG.

Hasil penelitian ini sejalan dengan temuan penelitian yang dilakukan oleh Batool, Sajid, \& Raza S (2012) yang menyimpulkan bahwa implementasi Sistem Informasi Manajemen Sumber Daya Manusia mengalami beberapa kendala seperti kurangnya keahlian, masalah teknis, kurangnya dana, dan konsumsi waktu oleh staf yang tidak terlatih. Kendala anggaran dalam penerapan SIMPEG di BKPP Kabupaten Sukoharjo yang ditemukan dalam penelitian ini juga mendukung penelitian yang dilakukan oleh Kananu dan Nyageko (2016).

\section{KESIMPULAN}

\section{Kesimpulan}

a. Prosedur pelaksanaan SIMPEG di BKPP Kabupaten Sukoharjo terdiri dari sub sistem pengumpulan data, sub sistem input data, sub sistem pengolahan data dan sub sistem output informasi. Sumber data yang dijadikan dasar dalam pengelolaan SIMPEG berasal dari Formulir Isian Pegawai. SIMPEG didukung oleh komponen-komponen yang terdiri dari hardware (perangkat keras), software (perangkat lunak), database, sumber daya jaringan dan brainware (SDM) SIMPEG di BKPP Kabupaten Sukoharjo dapat diakses secara online mulai tahun 2017.

b. Informasi yang dihasilkan oleh SIMPEG di BKD saat ini sudah mampu untuk mendukung pengambilan keputusan dalam pelaksanaan penempatan, mutasi dan pensiun pegawai.

c. Kendala dalam penerapan Sistem Informasi Manajemen Kepegawaian di BKPP Kabupaten Sukoharjo yaitu: 1) Kendala Anggaran, 2) Keterlambatan dalam input data dan 3) Kurangnya pegawai pengelola SIMPEG.

\section{Implikasi}

Berdasarkan kesimpulan yang telah dikemukakan di atas, implikasi hasil penelitian adalah sebagai berikut

a. Adanya kekurangan yang dihadapi oleh BKPP Kabupaten Sukoharjo dalam penerapan SIMPEG dapat dijadikan sebagai bahan evaluasi untuk memperbaiki Sistem Informasi Manajemen Kepegawaian dengan melihat setiap komponennya, sehingga diharapkan dengan perbaikan tersebut akan memudahkan dalam pengelolaan data kepegawaian sehingga SIMPEG 
dapat berjalan optimal sebagai pendukung pelaksanaan manajemen kepegawaian.

b. Informasi SIMPEG yang belum sepenuhnya mendukung dalam pengambilan keputusan dalam pelaksanaan manajemen kepegawaian di BKPP Kabupaten Sukoharjo dapat dijadikan masukan untuk mengembangkan fitur-fitur dalam aplikasi SIMPEG sehingga informasi yang dihasilkan oleh SIMPEG lebih mampu dalam mendukung pengambilan keputusan di bidang kepegawaian.

c. Adanya kendala-kendala yang dihadapi dalam implementasi SIMPEG akan memacu Pimpinan dan staff yang bertanggungjawab dalam pengelolaan SIMPEG untuk dapat mengatasi dan mencari solusi berkenaan dengan kendala yang dihadapi saat ini sehingga dengan solusi tersebut SIMPEG di BKPP Kabupaten Sukoharjo akan dapat berjalan dengan baik.

\section{Saran}

Berdasarkan kesimpulan yang telah dikemukakan di atas, maka dapat dituliskan saran sebagai berikut.

a. Memberikan pelatihan tentang SIMPEG kepada seluruh staff di Sub Bidang Informasi Data Pegawai dan Kesejahteraan untuk mengatasi kendala terbatasnya SDM yang mengelola SIMPEG saat ini.

b. Melakukan penambahan personil yang bertanggungjawab mengelola SIMPEG untuk mengatasi kendala terbatasnya SDM yang mengelola SIMPEG saat ini.

c. Mengembangkan fitur yang ada dalam aplikasi SIMPEG sehingga informasi yang dihasilkan akan lebih mampu mendukung pengambilan keputusan dalam hal pelaksanaan manajemen kepegawaian di BKPP Kabupaten Sukoharjo.

d. Melakukan input data ke dalam aplikasi SIMPEG sesegera mugkin agar kendala keterlambatan dalam input data dapat diatasi dan SIMPEG mampu menghasilkan informasi yang valid dan akurat.

\section{DAFTAR PUSTAKA}

Anggadini, S. D. (2013). Analisis Sistem Informasi Manajemen Berbasis Komputer Dalam Proses Pengambilan Keputusan. Majalah Ilmiah Unikom.

Batool, S.Q, Sajid, M.A dan Raza, S.H. (2012). Benefits and Barriers of Human Resource Information System In Accounts Office \&Azad Jammu \&Kashmir Community Development Program. International Journal of Humanities and Social Science, 2(3),211-217, diambil dari http://www.ijhssnet.com/journals/Vol_2_No_3_February_2012/28.pdf

Beadles, Nicholas Aston II; Lowery, Christopher M.; dan Johns, Kim .(2005). The Impact of Human Resource Information Systems: An Exploratory Study in the Public Sector. Communications of the IIMA, 5 (4), 39-46, diambil dari https://core.ac.uk/download/pdf/55332428.pdf 
Indrajit, Richardus Eko. (2004). e-Government Strategi Pembangunan Dan Pengembangan Sistem Pelayanan Publik Berbasis Teknologi Digital. Yogyakarta:Andi Offset.

Irawan, H dan Waskito, Y. (2011). Analisa dan Perancangan Sistem Informasi Administrasi Kepegawaian Direktorat Jenderal Pengembangan Ekspor Nasional Kementrian Perdagangan R.I. BIT 8 (2), 53-62, diambil dari http://riset.budiluhur.ac.id/wpcontent/uploads/2013/10/AnalisaPrancanganSIAP_HendriIrawan.pdf

Ferdous, F, Chowdury, M.M dan Bhuiyan, F. (2015). Barriers to the Implementation of Human Resource Information Systems. Asian Journal of Management Sciences \& Education, 4 (1), 33 42 , diambil dari

https://pdfs.semanticscholar.org/79f1/26f05f663e630b9be7a2f9ca7e03360574fb.pdf

Kananu, K.M, dan Nyageko, M.O. (2016). Challenges and Strategies in the Implementation of Human Resource Information Systems in Kenyan Universities. Research on Humanities and Social Sciences, 6 (18), 148-160

Keputusan Menteri Dalam Negeri Nomor 17 Tahun 2000 tentang Sistem Informasi Manajemen Kepegawaian.

Kumorotomo W. \& Margono, S.A.(2004). Sistem Informasi Manajemen Dalam Organsasi Publik. Yogyakarta: Gama Press.

Lipursari, A. (2013). Peran Sistem Informasi Manajemen (SIM) dalam Pengambilan Keputusan. Jurnal Stie Semarang, 5 (1), 26-37

Ngai, E. and Wat, F. (2006), Human resource information systems: a review and empirical analysis, Personnel Review, 35 (3), 297-314, https://doi.org/10.1108/00483480610656702

Pratiwi, A. (2018). Implementasi Sistem Informasi Manajemen Kepegawaian (SIMPEG) sebagai Dasar Pengambilan Keputusan Bidang Sumber Daya Manusia (SDM) di BKD Kota Salatiga. Jurnal Mahasiswa Administrasi Negara (JMAN), 2 (2), 145-156

Suwatno dan Priansa, D.J. (2011). Manajemen Sumber Daya Manusia dalam Organisasi Publik dan Bisnis. Bandung: Alfabeta

Troshani, I., Jerram, C. dan Rao, H. S. (2011). Exploring The Public Sector Adoption of HRIS. Industrial Management \& Data Systems, 111 (3), 470-488, diambil dari https://doi.org/10.1108/02635571111118314

\section{UCAPAN TERIMA KASIH}

Penulis mengucapkan terimakasih kepada seluruh pegawai BKPP Kabupaten Sukoharjo atas bantuannya selama penelitian, keluarga, rekan sejawat yang membantu dalam penulisan artikel, editor jurnal efisiensi dan para pembaca yang telah meluangkan waktunya membaca artikel ini.

\section{PROFIL PENULIS}

Penulis merupakan dosen di Program Studi Pendidikan Administrasi Perkantoran Universitas Negeri Yogyakarta dengan jabatan Tenaga Pengajar, lulusan S1 Pendidikan Administrasi Perkantoran dan S2 Pendidikan Ekonomi Universitas Sebelas Maret Surakarta. 